Daimon. Revista Internacional de Filosofía, Suplemento no 8 (2020), pp. 183-196

ISSN: 1130-0507 (papel) y 1989-4651 (electrónico)

http://dx.doi.org/10.6018/daimon.381691

\title{
Carlos Astrada frente a la tercera visita de Ortega a la Argentina
}

\section{Carlos Astrada regarding Ortega's third visit to Argentina}

\author{
MARTÍN PRESTÍA*
}

\begin{abstract}
Resumen: El presente trabajo tiene como propósito poner de relieve un aspecto de la tercera visita de Ortega y Gasset a la Argentina aún desconocido por la crítica: la recepción de las lecciones que el español dictara en Amigos del Arte por parte de Carlos Astrada (1894-1970), quien fuera uno de los mayores filósofos argentinos del siglo XX, introductor de la filosofía de Martin Heidegger a la Argentina y difusor del pensamiento de Edmund Husserl y Max Scheler. La recensión de las lecciones por parte de Astrada apareció en un artículo publicado en el diario nacionalista El Pampero bajo el título de "El Centauro y los Centauristas. La originalidad del señor Ortega y Gasset" el 23 de noviembre de 1939, que hemos encontrado en el curso de nuestras investigaciones y que presentamos a continuación. La misma siguió el tono general de «marginación» con el que Ortega fue recibido por el ambiente
\end{abstract}

\begin{abstract}
This paper aims to highlight an aspect of Ortega y Gasset's third visit to Argentina, still unknown by critics: the reception of the lessons he dictated in Amigos del Arte by Carlos Astrada (1894-1970), one of the most important Argentine philosophers of the twentieth century, the main introducer of Martin Heidegger's philosophy to Argentina, and a spreader of Edmund Husserl and Max Scheler's thought. The review of the lessons appeared in an article published in the nationalist newspaper El Pampero under the title "El Centauro y los Centauristas. La originalidad del señor Ortega y Gasset" on November 23, 1939, which I have found in the course of my investigations. It shares the general tone of "marginalization" with which Ortega was received by the Argentine intellectual and academic environment. Likewise, this reception is one of the instances of a complex philosophical rela-
\end{abstract}

Recibido: 30/05/2019. Aceptado: 10/07/2019.

* El autor es Maestrando (etapa de tesis) en Ciencia Política por la Universidad Nacional de San Martín (IDAESUNSAM) y Doctorando en Ciencias Sociales por la Universidad de Buenos Aires (UBA), con una Beca Doctoral del Consejo Nacional de Investigaciones Científicas y Técnicas. Es Profesor Adjunto de Ciencia Política en la Universidad de Ciencias Empresariales y Sociales (UCES) y Profesor Adjunto de Historia Económica Contemporánea en la Universidad Nacional de Lomas de Zamora (UNLZ). Es Director e Investigador del Círculo de Estudio "Comunidad, mito, poesía. Contornos de lo político" (IDAES-UNSAM) e Investigador del Instituto de Investigaciones Gino Germani de la Universidad de Buenos Aires (IIGG-UBA). Su principal línea de investigación actual es la filosofía política de Carlos Astrada. Es autor del Estudio Preliminar y compilador del libro Carlos Astrada. Escritos escogidos. Artículos, conferencias, ensayos, manifiestos (1916-1943) [En prensa]. Publicaciones recientes: "Del «Año del Libertador» a la «Campaña Echeverría»: las figuras de Carlos Astrada y Héctor P. Agosti en la disputa por la historia nacional", Monograma. Revista Iberoamericana de Cultura y Pensamiento, n. 3, noviembre de 2018, pp. 101-120 y "Universidad y ethos nacional. La Reforma universitaria de 1918 en el pensamiento de Carlos Astrada", Questiones de Ruptura. Revista interdisciplinar de las Ciencias Sociales de América Latina, vol. 2, n²1, enero-junio de 2018,pp.82-98. E-mail: martinprestia@ gmail.com. 
intelectual y académico argentino. Asimismo, esta recepción es una de las instancias de una compleja relación filosófica del argentino con la figura del español, que en el presente trabajo sólo podemos aspirar a apuntar brevemente.

Palabras clave: José Ortega y Gasset, Carlos Astrada, filosofía argentina, existencialismo. tionship between the Argentine philosopher and Ortega, which in the present work I can only aspire to briefly point out.

Keywords: José Ortega y Gasset, Carlos Astrada, Argentinian Philosophy, existentialism.

El tercer viaje de Ortega y Gasset a la Argentina es, como puede inferirse del célebre trabajo de Tzvi Médin (1994, 123 ss.), un viaje ambiguo. La disciplina filosófica argentina, que tanto le debía en su despliegue - fundamentalmente a raíz de la visita inaugural, de 1916-, recibe al madrileño con la sospecha de que su palabra no tiene ya el ademán creador que le reconocía antaño. La que una vez fuera «la nueva generación» americana, portadora de una «nueva sensibilidad» y protagonista de la Reforma universitaria de 1918, no lo admite ya en la galería triunfal de sus «maestros». En contraste, mientras los ambientes específicamente intelectuales prácticamente no recogen el eco de su visita, la popularidad orteguiana crece sostenida y ampliamente, lo cual se comprobó en sucesivas reediciones de algunos de sus libros de años anteriores. De ese modo, "a pesar de la marginación que sufrió Ortega especialmente por parte de los círculos académicos profesionales, su obra continuó siendo parte esencial de la cultura argentina en esos años flacos para el autor en lo personal" (Médin, 1994, 131). El trabajo de Médin tiene la virtud de mostrar que, para comprender ese doble aspecto del tercer viaje orteguiano - de «marginación» al mismo tiempo que de «vigencia», si bien en dos ámbitos distintos - , es necesario considerar tanto los motivos que hacen a la estricta disciplina filosófica como los políticos y, en sentido amplio, "culturales".

En las lecciones de 1939 pronunciadas en Amigos del Arte Ortega tiene que aclarar una vez más - que lo que él hace es, ante todo, filosofía, y no literatura, y la defensa de esa acusación es un claro síntoma del lugar en que los filósofos argentinos, en pleno proceso de profesionalización, lo han colocado․ Así, en la cuarta lección decía: “[p]erdónenme que les diga - y lo saben quienes de antiguo me leen o me escuchan - , yo no hago nunca sólo literatura. No porque me parezca mal la literatura sino porque ella no es mi quehacer" (Ortega y Gasset, [1939] 2009: 310). Y reforzaba esa idea al finalizar la sexta y última de las lecciones impartidas en 1939 en aquella institución, recurriendo a su célebre imagen del «centauro» y con un dejo irónico:

[y] por eso me importan tan poco discusiones como esa discusión que se discute, no en los pueblos creadores pero sí en los otros, discusión que durante toda mi vida me acompaña humilde y caricaturesca como si fuera una sombra, [...] la discusión, señores, de que si soy literato o filósofo. [...] ¿Por qué no de ser, en definitiva, imposible saber si soy lo uno o lo otro? ¿Por qué no había de ser centauro de ambos? Se trataría no más de una especie nueva, suponiendo que fuera nueva - que no lo es ni mucho menos - , pero no quiero ampararme en nombres demasiado famosos; se trataría en

1 Sobre la profesionalización de la filosofía argentina, cf. Alberini (1949), Oviedo (2005), Pró (1965), Romero (1950; 1952), entre otros. 
todo caso de una especie insólita. Y como el espíritu, cualquiera sea su dosis genial o modesta, es siempre fecundo, quiere decirse que, centauro yo, mi influjo suscitaría algunos centauritos, a quienes tal vez no les fuese del todo mal en la vida... (Ortega y Gasset, [1939] 2009, 362).

Como es sabido, mucho había contribuido al distanciamiento de los ambientes filosóficos la poco comprendida sugestión orteguiana contenida en los artículos "La pampa... promesas" y "El hombre a la defensiva", escritos en 1929 tras su segundo viaje a la Argentina. Asimismo, más allá de las cuestiones que atienen a la labor filosófica, Ortega fue presa de su indefinición ante el franquismo y la Segunda Guerra Mundial. Los ambientes republicanos y democráticos le exigen una toma de partido, que no llega, mientras que algunos grupos católicos, nacionalistas y pro-franquistas reivindican, de manera un tanto paradójica, su pensamiento - como es el caso emblemático de Máximo Etchecopar, con quien Ortega tuvo una fuerte vinculación por estos años, pero también Marcelo Sánchez Sorondo y César Pico, entre otros (Médin, 1994, 126-7). En paralelo, se produce un alejamiento de Ortega de la revista de marcada tendencia aliadófila $S u r^{2}$, de la que otrora fuera un referente, como así también de reconocidos intelectuales republicanos como Francisco Romero - por motivos relacionados con la edición de sus libros (Médin, 1994, 125). La imposibilidad de Ortega de obtener una cátedra en la Facultad de Filosofía y Letras de la Universidad de Buenos Aires, la pérdida de su sueldo fijo como asesor de la editorial Espasa-Calpe, la fugaz reconciliación y nueva ruptura con el diario La Nación y los intentos truncos por lanzar una editorial como la que había llevado adelante en España coronan un ciclo de decepciones, distanciamientos y fracasos (Campomar, 1997, 146-7; Zamora Bonilla, 2002, 444-6). El tercer viaje de Ortega es, así, uno de sus períodos más oscuros, y en una carta a Victoria Ocampo fechada el 9 de octubre de 1941 le confiesa: "sin posible comparación atravieso la etapa más dura de mi vida" (Médin, 1994, 124) .

Todo lo que hemos dicho hasta aquí es conocido por cualquier estudioso de Ortega. En el presente escrito pretendemos poner de relieve un aspecto de ese viaje aún desconocido por la crítica: la recepción de las lecciones que el madrileño dictara en Amigos del Arte por parte de Carlos Astrada (1894-1970), quien fuera uno de los mayores filósofos argentinos del siglo XX, principal introductor de la filosofía heideggeriana a nuestro país, y difusor del pensamiento de Edmund Husserl y Max Scheler. En ese sentido, el presente artículo no quiere ser sino la introducción a un documento, "El Centauro y los Centauristas. La originalidad del señor Ortega y Gasset" (1939), texto que presentamos a continuación ${ }^{4}$. La breve recensión de las conferencias en Amigos del Arte por parte de Astrada - a tono con el modo en que Ortega fue recibido por el ambiente intelectual y académico - se engarza

2 Apenas desatada la guerra, la revista dirigida por Victoria Ocampo dedicará un número especial a la conflagración, tomando una activa posición militante a favor de los aliados, lo que contrastaba con la postura indefinida de Ortega.

3 Para una exposición exhaustiva de la tercera visita de Ortega a la Argentina y sus diversas intervenciones públicas, como así también la recepción de las mismas por parte de diversos periódicos y revistas culturales, cf. Campomar (2016).

4 El texto es también desconocido por la crítica astradiana; lo hemos encontrado en el curso de nuestras investigaciones en torno a la obra y vida del filósofo argentino. 
como un eslabón más a la compleja relación del argentino con la figura del español, que aquí sólo podemos aspirar a apuntar brevemente ${ }^{5}$.

\section{Ortega y Gasset en la trayectoria intelectual de Carlos Astrada}

Como sugeríamos algunos renglones más arriba, Ortega y Gasset fue, junto a Miguel de Unamuno y, en menor medida, Eugenio D'Ors, parte de aquella serie de maestros que la generación reformista «se dio a sí misma», según el célebre pasaje del Manifiesto Liminar de $1918^{6}$. De esas jornadas formó parte activa Astrada, integrando el ala libertaria, romántica y vitalista de la Reforma, que buscó impugnar la hegemonía que la Iglesia católica tenía en Córdoba sobre la cultura y la educación —en términos amplios, no sólo universitaria7. Asimismo, la formación juvenil de Astrada tuvo lugar en el ámbito de una reacción contra el positivismo, la filosofía e ideología dominantes en el país. En ese sentido, el ala de la Reforma que integraba nuestro autor también alzó la bandera de lo que se pretendía una más amplia y adecuada concepción de la tarea científica y el pensamiento humanos.

El problema del positivismo era medular en Buenos Aires y La Plata, donde dominaba los claustros universitarios. La importancia que desde el decanato y la cátedra tuvieron los filósofos Alejandro Korn y Coriolano Alberini en la devaluación del positivismo — desde antes, incluso, de la Reforma universitaria - no puede subestimarse (Velarde Cañazares, 2013: 65), como así tampoco la actuación de Rodolfo Rivarola, decano de la facultad de Filosofía. El primer viaje de Ortega a la Argentina se engarzó a la reacción contra el positivismo que estamos describiendo ${ }^{8}$. La impugnación que Ortega realizara del positivismo le valió entreverarse en una disputa pública con Alberto Palcos, que defendía posiciones cercanas a las de José Ingenieros - que era el principal destinatario de los ataques de Ortega y decidió no entrar en la polémica de manera directa ${ }^{9}$. No obstante, la importancia del primer

5 Más allá de la presencia textual de Ortega en los escritos astradianos, falta aún un estudio que pueda mostrar las posibles influencias del madrileño en el argentino y, aún, las afinidades temáticas entre ambos.

6 "La juventud vive siempre en trance de heroísmo. Es desinteresada, es pura. No ha tenido tiempo aún de contaminarse. No se equivoca nunca en la elección de sus propios maestros. Ante los jóvenes no se hace mérito adulando o comprando. Hay que dejar que ellos mismos elijan sus maestros y directores, seguros de que el acierto ha de coronar sus determinaciones. En adelante solo podrán ser maestros en la futura república universitaria los verdaderos constructores de alma, los creadores de verdad, de belleza y de bien" (Roca, 1918, 79).

7 Para una mirada de la relación de Carlos Astrada con el movimiento reformista universitario de 1918, en la que se incluye una serie de breves consideraciones en torno a la influencia de Ortega entre la «nueva generación», cf. Prestía (2018).

8 José Ortega y Gasset llegó a la Argentina en julio de 1916 y permaneció hasta finales de año, pasando por varias ciudades: la capital del país, La Plata, Rosario, Mendoza, Tucumán y la propia Córdoba, por nombrar las principales escalas de su viaje. Para una exposición exhaustiva del primer viaje de Ortega y sus diversas intervenciones públicas — conferencias, cursos, artículos_-, como así también la recepción de las mismas por parte de diversos periódicos y revistas culturales, cf. Campomar (2009).

9 En un curso dictado durante los primeros meses de 1916, antes de la llegada del madrileño al país, Ingenieros menciona a Ortega, colocándolo a la cabeza del grupo de "los neokantianos españoles" que "cultivan el derecho y no desdeñan las matemáticas", "no profesan las ciencias naturales" y "entienden ejercer una función moral y política". Ingenieros admite además que, aunque no se ha "exteriorizado aún en obras filosóficas, su influencia cultural es ya muy apreciable". Como parte del grupo destaca, además del "distinguidísimo profesor José Ortega y Gasset", a "Manuel G. Morente, Luis de Zulueta, Domingo Barnés, Francisco Rivera y Pastor, De los Ríos y otros jóvenes". La mención de Ortega, halagüeña, es en realidad ambigua, dada la caracterización gene- 
viaje del español no se limitó a ello. Ortega dictó una serie de conferencias fundamentales para el despliegue de la filosofía en nuestro país, introduciendo, entre otros autores alemanes, a Edmund Husserl, Max Scheler y Heinrich Rickert, al tiempo que dedicó un curso a la Crítica de la razón pura de Kant. Asimismo, Ortega legó una serie de términos que se harían verbo y carne en el movimiento reformista: la «nueva generación» y la nueva sensibilidad, que venían a ensamblarse con el modernismo latinoamericano y el juvenilismo romántico de Ariel $^{10}$. Como habrían de reconocer muchos años después los propios Korn (1936: 280) y Alberini (1949: 73) recordando la visita de 1916, Ortega y Gasset resultó, entre nosotros, «más que un hombre, un acontecimiento». Su presencia en la obra juvenil astradiana es innegable: durante la década de 1920 el argentino lo cita copiosamente, e incluso toma parte de su lenguaje para desarrollar sus propias ideas, siempre con sentido crítico ${ }^{11}$. En sus textos juveniles celebra en el madrileño al hombre preclaro de la «nueva sensibilidad», al "espíritu de vanguardia y fino avizor de las variaciones que se insinúan en la sensibilidad contemporánea" $(1924,185)$, a "una de las mentes más calificadas de esta hora ortal de la sensibilidad de nuestro tiempo" $(1926,2)$.

En 1927 el filósofo argentino gana una beca para el perfeccionamiento de sus estudios en Europa y parte hacia Alemania en busca de recibir de primera mano la formación filosófica que, hasta ese momento, había cultivado en gran parte de manera autodidacta. En su primer semestre en Colonia asiste, en la Facultad de Filosofía, a las determinantes lecciones de Max Scheler sobre Antropología filosófica. Con él pronto traba una relación de amistad y discipulazgo, hasta que la muerte arrebata al maestro el 19 de mayo de 1928, segando la órbita vital de un pensador que, con tan sólo 53 años, se encontraba en la plenitud de sus posibilidades, perfilándose como una de las mentes más poderosas y penetrantes de Alemania. Tras el deceso de Scheler, Astrada se radica en Friburgo, donde se produce el encuentro determinante con la filosofía «existencial» de Martin Heidegger, que estaba en el centro de las discusiones filosóficas a raíz de la publicación de Sein und Zeit [Ser y tiempo] (1927), su obra señera. A partir de entonces, y hasta el final de sus días, la producción astradiana no abandonó la senda abierta por el filósofo de Messkirch: incluso las críticas que desliza - al «segundo» Heidegger, por ejemplo - son realizadas bajo la órbita de su pensamiento. También en Friburgo estudia con Edmund Husserl - con quien entabla una relación de

ral que hace Ingenieros del neokantismo y de la labor del grupo: “[a]lgunos universitarios jóvenes, convencidos de que no hay tradición filosófica española han creído de provecho introducir en España una de las escuelas que están de moda en Europa. Dado el profundo sentimiento antifrancés de los españoles, en vez de acudir a Bergson optaron por el neokantismo de Marburgo, su equivalente alemán como filosofía ecléctica, equidistante de la atrasada escolástica española y del naturalísimo científico muy resistido en España" (Ingenieros, [1916] 1957: 93). Precisamente este "naturalismo científico" era la posición que encarnaba Ingenieros.

10 La bibliografía en torno a este tema en la obra de Ortega y Gasset es muy numerosa; para una síntesis del modo en que esos y otros conceptos fueron apropiados por la vanguardia cultural latinoamericana, cf. Médin, T (1994: 16 ss.). Asimismo, prácticamente toda la bibliografía especializada en torno a la generación reformista coincide en señalar, junto al español, los afluentes arielista y modernista.

11 Una mirada rápida a los títulos de algunos trabajos de la época - y también de años posteriores - lo confirma: "La deshumanización de Occidente" (1925); "Imperativo de Plasticidad" (escrito en 1926 y publicado en 1927), "Meditación de Rumipal" (escrito en 1935 y publicado en 1939); "Para un Programa de Vida Argentina" (1943). A ello hay que sumarle la utilización de algunos términos típicamente orteguianos, tales como «nueva sensibilidad», «nueva generación», «fondo insobornable», entre otros. 
amistad—, Nicolai Hartmann, Helmuth Plessner, Oskar Becker, Martin Hönecker y Fritz Kauffmann. En diciembre de 1930 retorna a Colonia y se matricula en la Universidad de Bonn, donde asiste a un curso de Estética con Friedrich Behn hasta que debe emprender el regreso a su país, en 1931, impelido por las condiciones económicas desfavorables. En sus cuatro años de estadía Astrada estrechó vínculos, dentro y fuera de los claustros, con filósofos de la talla de Hans-Georg Gadamer, Otto Bollnow, Herbert Marcuse, Ernesto Grassi, Karl Löwith, Eugen Fink, Richard Kroner y Wilhem Szilazi, entre otros ${ }^{12}$.

Aún radicado en Alemania, y en los años siguientes a la muerte de Max Scheler, hasta 1931, Astrada dedica tres artículos a las últimas direcciones de la filosofía de quien fuera su maestro. De ellos destacamos "Max Scheler y el problema de una antropología filosófica" (1928) en el cual, tras presentar los lineamientos esenciales de la concepción scheleriana del ser humano y su «puesto en el cosmos», menciona las indagaciones de "otros filósofos representativos" tales como Simmel y Ortega y Gasset — de quien cita "Vitalidad, alma, espíritu" (1924) - , que confirmarían la necesidad de establecer una antropología filosófica como punto de partida de toda otra indagación filosófica. En ese sentido, uno de los puntos interesantes de estos artículos reside en la inicial impugnación de las posiciones heideggerianas de Sein und Zeit, amparado en las críticas y objeciones que desliza el propio Scheler. La analítica existencial heideggeriana recorre una senda del pensar divergente a la de una antropología filosófica, que por esos años nuestro autor creía el desarrollo necesario de una filosofía «a la altura de los tiempos». Así, en las primeras líneas de su artículo "La problemática de la filosofía actual" (1929) - en lo esencial, una recensión del célebre debate de Davos protagonizado por Martin Heidegger y Ernst Cassirer - menciona la "fundamentación de la metafísica" y la "antropología filosófica" como las "dos direcciones básicas" del pensamiento filosófico alemán contemporáneo. De esa relación afirma: “[1]a interrogación sobre la metafísica se funda en la interrogación acerca del hombre. La Metafísica por tanto ha de ser referida a la antropología filosófica" (Astrada, 1929, 115). Estas lecturas tentativas hallaron su "criba ontológica" - según feliz expresión de Guillermo David (2004, 79) - recién en El juego existencial (1933), primer libro de Carlos Astrada, en el que saluda a Heidegger como "el filósofo de más significación de occidente, en la hora actual" (Astrada, 1933a, 9). En él realiza un ajuste de cuentas, en nombre de la analítica existencial del Dasein, con toda su formación filosófica previa: Max Scheler, Georg Simmel, Edmund Husserl, Wilhem Dilthey y José Ortega y Gasset.

En lo que concierne a nuestro tema, en el capítulo III, "Coexistencia y oposición sujetoobjeto", Astrada expresa que el punto de vista de Ortega en torno a la relación del «yo» y los «otros» "no es más que el inoperante de la «Einfühlung»", esto es, "la «proyección sentimental» o «endopatía» de los psicólogos alemanes" (Astrada, 1933a, 92). Para Astrada, tal visión queda alejada de toda posibilidad de dar con la estructura ontológica de la existencia que, en tanto «estar en el mundo», es siempre un existir con otros, un «coexistir». En ese sentido, "[l]a endopatía, tal como nos dice Heidegger, no constituye el coexistir, sino inversamente es a base de este último que aquella es posible, siendo motivada (y aún más, justificada) por obra de los modos deficientes y predominantes del coexistir" (Astrada, 1933a,

12 Para una rica exposición biográfica de los años de estadía europea de Carlos Astrada, ilustrada con numerosas piezas de su correspondencia personal, cf. David (2004, 45-78). 
91). Y ya comentando directamente a Ortega dice que de sus afirmaciones "está ausente la menor sospecha de la verdadera estructura ontológica de la existencia; vale decir, de que la comprensión de los «otros» yace implicada en la comprensión del ser de la propia existencia” (1933a, 92). Por último, Astrada apunta también, siempre en línea con la problemática desplegada por Heidegger y de manera crítica, que en el "escritor español" - y el uso de esa expresión para caracterizar a Ortega no es casual - "no hay estricta discriminación entre vida y existencia" (1933a, 92). Que en su primer libro dedique tanto espacio a la impugnación de una visión a la que considera "inoperante" - y a un "escritor" - nos habla, en verdad, de la importancia de la figura de Ortega y Gasset y del influjo que su palabra irradiaba sobre el público filosófico local.

En el mismo 1933 realiza otro ataque a la filosofía orteguiana. Aparece en el marco de la edición de la conferencia de Astrada "Heidegger y Marx. La historia como posibilidad fundamental de la existencia humana", dictada en el año anterior, y en la que apuntaba a establecer un vínculo entre el "el más grande metafísico occidental de esta hora”, y "el economista teórico y revolucionario práctico de tan hondo influjo en el área histórica de las discusiones y luchas del presente" (1933b, 1053). Esa línea, interrumpida durante las décadas de 1930 y 1940, habría de ser, en definitiva, la indagación a la que dedicó buena parte de su filosofía política final, tras su viraje al marxismo, y que sintetizó bajo el nombre de «humanismo de la libertad». En una nota a pie de página de la edición de la conferencia citada critica, un tanto apresuradamente - cosa que, lamentablemente, fue en Astrada una práctica habitual que resintió parte de sus desarrollos-, la noción de «circunstancia» de Ortega, al considerarla ajena a una indagación ontológica como las que alcanzan Marx y Heidegger y, como tal, insuficiente (1933b, 1058).

Creemos, sin temor a incurrir en una exageración, que lo que está detrás de estas críticas es, a un tiempo, cierta pretensión de «liderazgo» filosófico en el ámbito hispanoparlante, como así también una disputa por la autonomía intelectual de Latinoamérica, particularmente de Argentina ${ }^{13}$. De algún modo, la impugnación se trata de un secreto «parricidio», gesto y proceder ante el que prácticamente todo filósofo de fuste se encuentra en su vida. No obstante, más allá de las modulaciones de carácter personal - donde entra a jugar incluso la vanidad-, estos movimientos pueden leerse como otros tantos episodios del proceso de profesionalización de la disciplina filosófica argentina.

Las líneas que planteamos se ven confirmadas al año siguiente, en junio de 1934, cuando Astrada escribe una violenta diatriba con motivo de la publicación del trabajo de Ortega "Guillermo Dilthey y la idea de la vida" en Revista de Occidente ${ }^{14}$. En su ensayo, Ortega menciona al filósofo Francisco Romero ${ }^{15}$ como el primer autor que ha presentado una exposición sobre el pensamiento diltheyano en habla castellana:

13 Cabe destacar que, por estos años, Astrada comienza a elaborar su pensamiento en torno al "ser nacional" argentino, con el artículo "La existencia pampeana" (1934).

14 El ensayo de Ortega fue publicado originalmente en los números 125, 126 y 127 de la Revista de Occidente en noviembre, diciembre y enero de 1933 y 1934 respectivamente.

15 Francisco Romero y Carlos Astrada aún mantenían vínculos por esos años, que se romperán hacia el final de la década por motivos políticos. Un testimonio de esa relación es la carta que José Babini, matemático e historiador de la ciencia, le envía a Romero el 27 de abril de 1934, en la que menciona el ensayo de Ortega y refiere haber comentado con Astrada "el desconocimiento de Ortega respecto a las contribuciones americanas 
[a]l corregir estas pruebas veo el anuncio de un ciclo de tres lecciones que sobre Dilthey habrá dado a estas horas D. Francisco Romero en la Facultad de Filosofía y Letras de Buenos Aires. Tal curso habrá sido la primera contribución hispánica - el autor nació en España - al estudio de Dilthey, y es seguro que, además, será muy estimable trabajo, dadas la serenidad y cuidadosa información de este excelente profesor (Ortega, [1933] 2004, 249).

El artículo de Astrada, “Contribución argentina y española sobre Dilthey. El caso del filósofo español Ortega y Gasset", pretende responder al juego de «precursiones» que plantea Ortega. Así, tras criticar la tan declamada "originalidad" de Ortega y realizar un comentario sobre la explicación - y justificación - del "retardo" de éste en llegar al pensamiento de Dilthey, termina por reclamar la «paternidad» en la introducción de Dilthey al español. Aunque la cita es algo extensa, vale la pena reponerla para poner de manifiesto el carácter virulento, francamente irónico, de la pluma astradiana:

[e]l señor Ortega dice, en una de las notas a la primera parte de su trabajo, que "no ha sido traducida al español, que yo sepa, ni una sola línea de Dilthey" y que "no habrá más de cuatro o cinco personas, si las hay, en el mundo de habla española, que conozcan su obra"

[...] Habrá sido, sin duda, una sorpresa para el escritor español que una de las "cuatro o cinco personas" que conocen a Dilthey se le haya anticipado en contribuir a su estudio. Pero se consuela haciendo constar que el señor Romero es español. Para el señor Ortega tenía suma importancia dar a entender que, en lo que a labor intelectual respecta, España es la metrópoli y la Argentina y los demás países latinoamericanos sus colonias. Digamos que el señor Romero no sólo se ha anticipado a su compatriota con ese ciclo de tres clases sobre Dilthey (iniciadas el 22 de noviembre), sino que en 1930 publicó un artículo sobre "Guillermo Dilthey" en [la revista] Humanidades de La Plata. En dicho artículo el señor Romero se refiere al carácter de la labor de Dilthey y hace algunas consideraciones en torno a la concepción de la psicología de éste. Hasta aquí la contribución española sobre Guillermo Dilthey. Ahora vamos a documentar una contribución argentina al estudio y conocimiento de la obra del ilustre creador de las "Ciencias del espíritu” (Astrada, 1934, 9).

A continuación, Astrada pasa revista pormenorizadamente a sus propias «contribuciones» a la difusión del pensamiento de Dilthey al español, que se inician con un trabajo que data de 1927. Las repetidas incursiones en el pensamiento de Dilthey evidenciarían, según Astrada, que la suya es una "sostenida preocupación por el pensamiento del germano", que llevó a colocarlo, desde un primer momento, en "un lugar de primer rango en la filosofía contemporánea". Con ello recalca que "en el «mundo de habla española», fue un argentino, que

de Dilthey" - aunque aclara: "[1]a pretensión de que Ortega conociera la conferencia de Astrada ["El aporte gnoseológico de Dilthey”, dictada el 28 de octubre de 1932 en la Facultad de Ciencias Económicas de la ciudad de Rosario] [...] solo aparecida publicada extractada en diarios locales, es excesiva y sólo se le puede ocurrir a Astrada que en general juzga algo despectivamente a Ortega" (Romero, 2017: 73). 
sepamos, quien primero se ocupó de Guillermo Dilthey" $(1934,9)^{16}$. El artículo de Astrada continúa - no sin cierto patetismo y pedantería - con una crítica de la labor de traducción llevada adelante por la biblioteca de Revista de Occidente, que Ortega dirige. Una vez más, lo que se disputa con ello es la autonomía intelectual del continente americano; sus filósofos, en trance de profesionalización, pueden acudir a las fuentes originales, y ello "sin vernos obligados a acudir a las traducciones no siempre cuidadas y a veces malas que publica la biblioteca de esa revista" $(1934,9)$.

\section{El tercer viaje de Ortega}

Astrada repetirá algunos de estos gestos en la tercera y última visita de Ortega a nuestro país, en el texto que presentamos a continuación, "El Centauro y los Centauristas. La originalidad del señor Ortega y Gasset". El artículo fue publicado con el pseudónimo de "Braulio Marín" en el diario nacionalista El Pampero el día 23 de noviembre de 1939, es decir, algunas semanas después de la última de las lecciones pronunciadas por Ortega en Amigos del Arte ese año, que el argentino comenta. El Pampero defendía posiciones neutralistas en la guerra, que se combinaban con abiertas simpatías por el Eje. Por ese entonces Astrada colaboraba aún con la revista Sur y el diario La Nación, medios aliadófilos y tradicionales tribunas de pensamiento orteguiano - lo que puede explicar, en parte, el uso de pseudónimo. No obstante, su última colaboración con la revista de Victoria Ocampo será, precisamente, en noviembre de 1939 (Sur, n62, Año IX), con el artículo "La antropología filosófica y su problema", mientras que el último ensayo publicado en el diario de la familia Mitre será "Rilke y la muerte propia", el 14 de abril de 1940. Presumiblemente, la interrupción de las colaboraciones se deba a la posición que ambos medios adoptan en la conflagración bélica, que contrastará con la participación de Astrada en diversas publicaciones periódicas y círculos político-culturales «neutralistas», algunos de ellos germanófilos, durante los primeros años de la década de 1940.

En efecto, el filo de las décadas de 1930 y 1940 encuentra a Astrada desempeñando actividades de «militancia» nacionalista, compartiendo espacios con intelectuales de similar tendencia, muchos de ellos católicos —él, que desde su juventud había sido rabiosamente anti-clerical y ya en sus años de reformista había impugnado el tomismo. Incluso publica algunos artículos en medios afines a esa cosmovisión, que muchas veces se completaba con una posición hispanista - como el periódico Cabildo y la revista Nueva Política. Asimismo, en el trienio 1940-1942 firma varios manifiestos y proclamas junto a los ya citados Máximo Etchecopar, Marcelo Sánchez Sorondo y César Pico —además de Homero Guglielmini, Nimio de Anquín, Leonardo Castellani, Ramón Doll y Leopoldo Marechal, entre otros. En el contexto de la Segunda Guerra Mundial y con un gobierno nacional fraudulento y de tendencia aliadófila los debates específicamente filosóficos quedan en un segundo plano y gana lugar la proclama por la neutralidad en el conflicto bélico y la «defensa de la soberanía». En ese sentido, son también los años previos al surgimiento del

16 En honor a la verdad, quien primero se ocupó del pensamiento de Dilthey en español fue Francisco Giner de los Ríos, en 1913 (Anderson Imbert, 1935, 144). 
peronismo, movimiento político que catalizará a buena parte de esos grupos y, ya desde el Estado, los colocará bajo su égida -incluyendo al propio Astrada ${ }^{17}$.

En "El Centauro y los Centauristas. La originalidad del señor Ortega y Gasset", Astrada continúa sus furibundas críticas al español, sin ahorrar denuestos a sus colegas sudamericanos. En las lecciones dictadas en Amigos del Arte, Ortega había abordado, principalmente, algunas dimensiones de su sociología filosófica - como los conceptos de «lo social», «uso», «hecho social»y las distinciones entre el «hombre»y la «gente»-, como así también consideraciones más vastas en torno a la vida humana sobre las que aquellas se emplazan - la vida como «realidad radical» $\mathrm{y}$ «quehacer incesante» y el ser humano como faciendum antes que factum. Como lo sugiere el título del texto astradiano, las críticas, antes que específicamente filosóficas, están dirigidas contra los "alardes de originalidad" de Ortega; según Astrada, en sus conferencias el madrileño no habría hecho sino repetir algunas líneas de la filosofía heideggeriana, en particular las relativas al "mundo humano circundante" 18 .

Astrada le concede a Ortega ideas originales, de vuelo filosófico - aunque aclara, mordaz, que son de filosofía "chica". Entre ellas destaca la noción de «proyecto vital», también llamada «programa de vida» en estas conferencias, de líneas afines a la problemática heideggeriana de la «autenticidad» o «propiedad» desplegada en Sein und Zeit - aunque en Heidegger ello tomará prontamente el carril de la «decisión anticipadora de la muerte», del todo ajena a Ortega ${ }^{19}$.

En su segunda conferencia, Ortega introduce su idea de «proyecto vital» del siguiente modo:

[e]l hombre no puede dar un solo paso sin anticipar, con más o menor claridad, dado su porvenir, todo lo que va a ser, se entiende - lo que ha resuelto ser en su vida entera. De modo que sobre el más sencillo de nuestros actos gravita íntegro el programa o proyecto general de nuestra vida que, claro está, puede cambiar - lo que digo es que cada acto va inspirado o informado por un programa integral de vida tal vez hoy distinto del de ayer. De modo que antes de hacer algo está ya ahí, en nuestra mente, una figura previa, un personaje imaginario que inspira a ser: un

17 Si bien la presencia de Astrada en el peronismo en el plano de la cultura es innegable - y puede especularse quizás sin demasiado temor a equivocarse que intentó ser una línea rectora del plano ideológico de tal movimiento político-, su labor filosófica no puede reducirse sin más a la de un "legitimador" del proyecto político justicialista. El peronismo, creemos, conmocionó de raíz su labor vital, en él advirtió las posibilidades de redención humana - como antes le había ocurrido con la Revolución Rusa y más tarde con la Revolución China - y a él se encolumnó desde el lugar que le estaba dado existencialmente, por temperamento y temple anímico, en función de una serie de «afinidades electivas» con su pensamiento y aspiraciones que el movimiento parecía desplegar. Para una mirada en torno a las diversas aristas de la compleja relación de Astrada con el peronismo, cf. David (2004: 141 ss.).

18 Es interesante notar que el propio Astrada identifica que existe un problema con la forma orteguiana de concebir la originalidad, constatación que invalidaría las pretensiones del español - como apunta el argentino- $-\ldots$ como asimismo las críticas de Astrada, quien también ha bebido de las «fuentes germánicas» para calmar su sed filosófica.

19 Astrada seguirá a su maestro de Friburgo en este punto; su libro El juego metafísico. Para una filosofía de la finitud (1942) será depurada síntesis de más de una década de reflexiones en torno a la problemática mentada, siempre bajo la inspiración de Heidegger. 
plan de existencia. Y este plan de vida, esto que yo llamo programa o proyecto vital, gravita sobre el más sencillo de nuestros actos, siendo él quien lo resuelve, quien lo determina (Ortega y Gasset, [1939] 2009, 288; énfasis original).

Tras la noción de «proyecto vital» se despliega la idea de que, arrojada hacia el futuro, la vida es "quehacer incesante" ([1939] 2009, 296). Ello compone un llamado a la identificación del quehacer que es, en cada caso individual, el auténtico - en vistas de la realidad radical que es «mi vida», «la vida de cada cual»- y a la creación - que es, antes que nada, creación de uno mismo, de esa "imagen o idea que en nosotros se ha formado del que tenemos que ser" ([1939] 2009, 297). En ese sentido, aclara Ortega, "cuál sea nuestro quehacer no nos es impuesto, sino que tenemos que elegírnoslo nosotros. Y eso - «tener que elegir»- es el quehacer de los quehaceres" ([1939] 2009: 296; énfasis original). Claro que ello no se despliega sobre un terreno infinito, sino que es la circunstancia la que traza, en definitiva, el perfil de nuestro quehacer, de nuestras posibilidades inmanentes. El ser humano "es siempre descendiente y heredero" ([1939] 2009, 355), vive en un mundo social que está ya labrado y nace a un conjunto de «usos» que son, precisamente, los que permiten que "el individuo vulgar tenga, en efecto, una vida, no genial, no personal, no plenamente auténtica, pero algo así como una vida; y logran, impiden que se anule él y se pierda en su propia inanidad" ([1939] 2009, 354; énfasis original).

El imperativo de autenticidad que propone Ortega tiene sus «afinidades electivas» con el pensamiento astradiano. Su aquilate está dado en la consigna pindárica «llega a ser el que eres», tan cara a ambos. En el caso de Astrada, sin embargo, el imperativo de autenticidad se ve prontamente referido, a lo largo de toda la década de 1940, a una indagación filosófico-política en torno al ser nacional y el establecimiento de las bases de un «programa de vida» argentino, que cristalizará en El mito gaucho (1948), una de sus obras más célebres. En ella describe, primeramente, la particularidad ontológica de la existencia argentina; según Astrada, el ser humano argentino tiene a la pampa como paisaje originario, que "no es exclusivamente el medio físico" sino "una definida modalidad o estructura existencial del hombre argentino", "constituto de su estructura ontológica" $(1948,14)$. $\mathrm{Si}$ el ser humano, por "la estructura esencial de su existencia [...] es primariamente un ser distante, excéntrico, es decir que, para él, el ser de su existencia es lo más lejano, al contrario de su vida psico-física, que es lo más próximo e inmediato" - y leemos en esta línea argumental la influencia heideggeriana en lo que respecta a la analítica existencial del Dasein-, el ser humano argentino, en razón del paisaje al que se ve arrojado en su existencia, la desolación telúrica de la pampa, es "doblemente excéntrico", un "ser de la lejanía", "una sombra en fuga y dispersión sobre su total melancolía, correlato espiritual de la infinitud monocorde de la extensión" $(1948,11)$. Por ello, si la revelación y posesión de su existencia están dadas al hombre por un retorno, por "un retomar o asir su ser desde ese alejamiento ontológico", el hombre argentino, en cambio, no puede en principio recuperarse, disperso en la melancolía totalizadora de la extensión pampeana $(1948,11)$. En El mito gaucho, Astrada traslada la caracterización de la peculiaridad ontológica del ser humano argentino al decurso histórico-político nacional. Según el pensador argentino, la inclinación del hombre pampeano a la dispersión estaría plasmada históricamente en una generación - la del ' $80-$, desertora de su propio destino y vicaria de modos de existencia 
ajenos, que desarrolló una "civilización de transplante" que convirtió a la pampa en un "Hinterland colonizado de acuerdo a las exigencias y para satisfacer las necesidades de la metrópoli europea" (1948: 36). Como reverso de la misma moneda, surgieron en nuestro país "formas institucionales y políticas informadas por principios y doctrinas extrañas a nuestra idiosincrasia y a nuestra realidad histórica" $(1948,36)$. De allí que "nuestra tarea" de argentinos sea "iluminar una presencia, una intención humana; ver al trasluz un ser, vale decir un ademán ontológico con sus raíces telúricas y espirituales, consignado a su órbita peculiar y con su posible proyección temporal", histórica $(1948,9)$. Siguiendo a Martin Heidegger, Astrada plantea que, para un pueblo, una posibilidad de Historia [Geschichte] no puede abrirse en el presente sino cuando se proyecta como su futuro una posibilidad no advenida u oculta de su pasado. El libro está abocado, entonces, a retomar un contacto con el «ser argentino» - contenido en un «mito» originario y prospectivo- como posibilidad de una existencia «propia», en una argumentación que no puede evitar, pese a los forcejeos, recaer en cierto esencialismo.

Es en El mito gaucho, precisamente, donde encontramos la vindicación tardía de Ortega, a quien caracteriza, a la par que a su círculo, como un faro en medio del oscurantismo franquista:

[f]elizmente, como compensación y contrapeso de ese espíritu cavernícola, que pretende ahogar la cultura española en una especie de Hurdes escolásticas, está ahí la valiosa labor de Ortega y Gasset, mente abierta a las más fecundas corrientes del pensamiento europeo, el espíritu más libre y universal que en filosofía, haya dado España. En su séquito, y en el dominio de la actividad filosófica, también cabe señalar destacados exponentes de la "España peregrina", incorporados ya a la vida intelectual de varios países de Hispano-América (Astrada, 1948, 101).

Siendo Astrada por ese entonces un intelectual que brinda su apoyo al peronismo, el comentario debe considerarse también en el marco de las discusiones libradas con los sectores que, al interior de ese movimiento político, defendían posiciones confesionales, en la disputa por su dirección cultural. El comentario fue quitado por Astrada de la edición de 1964 - es cierto: Ortega había muerto en 1955 - y, según Guillermo David $(2004,88)$, su hijo Rainer tenía órdenes expresas de su padre de remover toda referencia a José Ortega y Gasset, Miguel de Unamuno y Gabriel Marcel de futuras reediciones de El juego existencial, por haber perdido esos autores "toda relevancia filosófica".

Carlos Astrada, como tantos otros filósofos argentinos que se formaron por los años en que el influjo orteguiano fue mayor y que luego participarían del proceso de profesionalización e institucionalización de la filosofía, menospreció, a la postre, los alcances del pensamiento del español. Más sincero - $-\mathrm{y}$, francamente, también más justo - fue, por ejemplo, Luis Juan Guerrero (1899-1957), quien, en el prólogo a su Estética operatoria en sus tres direcciones, su obra señera, tras acusar la influencia, entre otros, de Vico y Hegel, de Husserl, Heidegger y Szilazi, estampó las emotivas palabras: “...y por detrás de todos estos reconocimientos, la proteica figura de Ortega y Gasset, de quien se podría decir como de Herder, al final de la época de Goethe y Hegel, que ya lo hemos olvidado a fuerza de estar presente en todos nosotros" ([1956] 2008, 14). 


\section{Referencias}

Alberini, C. (1949) "Sesión inaugural del Primer Congreso Nacional de Filosofía". En A.A.V.V. (1950). Actas del Primer Congreso Nacional de Filosofía, Tomo I, Sesión de Clausura. Buenos Aires: Universidad Nacional de Cuyo.

Anderson Imbert, E. (1935). "El pensamiento de Francisco Romero" ["Voluntad de sistema y pensamiento inquisitivo"]. En Speroni, J. L. (2001). El pensamiento de Francisco Romero. Buenos Aires: Edivérn.

Astrada, C. (1924). "El nuevo esteticismo". En Valoraciones, nIII, abril de 1924, La Plata, pp. $178-185$.

Astrada, C. (1926). "Pettoruti, artista de vanguardia". En Clarín, Año I, n 1, 30 de agosto de 1926, Córdoba, p. 2.

Astrada, C. (1929). "La problemática de la filosofía actual”. En Revista de la Universidad Nacional de Córdoba, Año 16, nº 7-8, septiembre-octubre de 1929, pp. 115-125.

Astrada, C. (1933a). El juego existencial. Buenos Aires: Babel.

Astrada, C. (1933b). "Heidegger y Marx. La historia como posibilidad fundamental de la existencia humana”. En Cursos y Conferencias. Revista del Colegio Libre de Estudios Superiores, Año II, n 10, abril de 1933, Buenos Aires, pp. 1053-1060.

Astrada, C. (1934). "Contribución argentina y española sobre Dilthey. El caso del filósofo español Ortega y Gasset”. En La capital, Rosario, 1 de junio de 1934, p. 9.

Astrada, C. (1948). El mito gaucho. Buenos Aires: Ediciones Cruz del Sur.

Campomar, M. (1997). "Los viajes de Ortega a la Argentina y la Institución Cultural Española”. En Molinuevo, J. (coord.). (1997). Ortega y la Argentina. Buenos Aires: Fondo de Cultura Económica.

Campomar, M. (2009). Ortega y Gasset en la curva histórica de la Institución Cultural Española. Biblioteca Nueva, Madrid.

Campomar, M. (2016). Ortega y Gasset. Luces y sombras del exilio argentino. Madrid: Biblioteca Nueva.

David, G. (2004). Carlos Astrada. La filosofía argentina. Buenos Aires: El cielo por asalto.

Guerrero, L. J., (2008). "Prólogo". En Estética operatoria en sus tres direcciones. Buenos Aires: Las cuarenta.

Ingenieros, J. (1957). La cultura filosófica en España. Buenos Aires: Elmer.

Korn, A. (1936). Influencias filosóficas en la evolución nacional. Buenos Aires: Editorial Claridad.

Médin, T. (1994). Ortega y Gasset en la cultura hispanoamericana. México: Fondo de Cultura Económica.

Ortega y Gasset (2004). "Guillermo Dilthey y la idea de la vida”. En Obras Completas. Tomo VI (1941-1955). Madrid: Taurus. [1933-4].

Ortega y Gasset (2009). "El Hombre y la Gente [Curso de 1939-1940]”. En Obras Completas. Tomo IX (1933-1948). Obra Póstuma. Madrid: Taurus.

Oviedo, G. (2005). "Historia autóctona de las ideas filosóficas y autonomismo intelectual: sobre la herencia argentina del siglo XX". En La Biblioteca, 2-3. Buenos Aires: Biblioteca Nacional de la República Argentina, pp. 76-97. 
Pró, D. (1965). "Periodización del pensamiento argentino". En Cuyo. Anuario de Historia del Pensamiento Argentino, 1. Mendoza: Universidad Nacional de Cuyo, Facultad de Filosofía y Letras, Instituto de Filosofía, pp. 7-42.

Prestía, M. (2018). "Universidad y ethos nacional. La Reforma universitaria de 1918 en el pensamiento de Carlos Astrada". En Questiones de Ruptura. Revista interdisciplinar de las Ciencias Sociales de América Latina, vol. 2, n¹, enero-junio de 2018, pp. 82-98. ISSN: 2538-9645.

Roca, D. (1918). "La juventud argentina de Córdoba a los hombres libres de Sudamérica" [Manifiesto Liminar]". En Kohan, N. (1999). Deodoro Roca, el hereje. B u e n o s Aires: Editorial Biblos.

Romero, F. (1950). "Sobre la normalidad filosófica”. En El hombre y la cultura. Buenos Aires: Espasa-Calpe.

Romero, F. (1952). "Indicaciones sobre la marcha del pensamiento filosófico en la Argentina”. En Sobre la filosofía en América. Buenos aires: Ed. Raigal.

Romero, F. (2017). Epistolario (Selección) (Comp.: Jalif, C.). Buenos Aires: Corregidor.

Velarde Cañazares, M. (2013). "La joven vanguardia filosófica argentina de la década de 1920”. Anuario de Filosofía Argentina y Americana (Universidad Nacional de Cuyo, Mendoza, Argentina), no. 3: 61-87.

Zamora Bonilla, J. (2002). Ortega y Gasset. Barcelona: Plaza Janés. 